\title{
Diversity did not influence soil water use of tree clusters in a temperate mixed forest
}

\author{
M. Meißner ${ }^{1, *}$, M. Köhler ${ }^{1, *}$, and D. Hölscher ${ }^{1}$ \\ ${ }^{1}$ Tropical Silviculture and Forest Ecology, Faculty of Forest Sciences and Forest Ecology, \\ Georg-August-Universität Göttingen, 37077 Göttingen, Germany \\ *These authors contributed equally to this work. \\ Correspondence to: M. Meißner (mmeissn3@gwdg.de)
}

Received: 14 December 2012 - Revised: 30 April 2013 - Accepted: 10 June 2013 - Published: 1 July 2013

\begin{abstract}
Compared to monocultures, diverse ecosystems are often expected to show more comprehensive resource use. However, with respect to diversity-soil-water-use relationships in forests, very little information is available. We analysed soil water uptake in 100 tree clusters differing in tree species diversity and species composition in the Hainich forest in central Germany. The clusters contained all possible combinations of five broadleaved tree species in one-, two- and three-species clusters (three diversity levels), replicated fourfold (20 one-species, 40 two-species and 40 three-species clusters). We estimated soil water uptake during a summer dry period in $0-0.3 \mathrm{~m}$ soil depth, based on throughfall and soil moisture measurements with a simple budgeting approach. Throughout the whole vegetation period in 2009 , soil water uptake was additionally determined at a higher temporal resolution and also for a greater part of the soil profile $(0-0.7 \mathrm{~m})$ on a subset of 16 intensive clusters. During the dry spell, mean soil water uptake was $1.9 \pm 0.1 \mathrm{~mm} \mathrm{day}^{-1}$ in $0-0.3 \mathrm{~m}$ (100 clusters) and $3.0 \pm 0.5 \mathrm{~mm} \mathrm{day}^{-1}$ in $0-0.7 \mathrm{~m}$ soil depth (16 clusters), respectively. Besides a slightly higher water use of Fraxinus clusters, we could not detect any effects of species identity or diversity on cluster water use. We discuss that water use may indeed be a conservative process, that differences in tree-species-specific traits may be compensated for by other factors such as herb layer coverage and tree spatial arrangement, and that diversitydriven differences in water use may arise only at a larger scale. We further conclude that with respect to stand water use "tree diversity" alone is not an appropriate simplification of the complex network of interactions between species traits, stand properties and environmental conditions that have varying influence on stand water use, both in space and time.
\end{abstract}

\section{Introduction}

Little information is available on the relationship between tree diversity and stand water use in temperate forests; but water use is most likely related to productivity in forest stands (Law et al., 2002). For grasslands, an increase in productivity with species diversity has been widely recorded (e.g. Hector et al., 1999). Evidence for a positive relationship between productivity and tree species diversity in forests is accumulating, indicated by a modelling exercise of competitive interactions of randomly chosen species (Tilman et al., 1997). From a forest succession model dealing with "real" species, the conclusion was derived that "tree diversity strongly influences primary productivity in European temperate forests across a wide range of sites with different climates through a strong complementarity effect" (Morin et al., 2011). Similar findings are also supported by some field studies: a positive relationship between tree species diversity and productivity was indicated in early successional and disturbed sclerophyllous and conifer forests before canopy closure (Vilà et al., 2005). In a Panamanian experimental plantation, mixed-species plots yielded on average 30-58\% higher summed tree basal area compared to monocultures after $5 \mathrm{yr}$ (Potvin and Gotelli, 2008). On 12000 permanent forest plots in Canada, a strong positive effect of biodiversity on tree productivity (controlled for environmental conditions) 
was obtained (Paquette and Messier, 2011). Another largescale study in Sweden across $400000 \mathrm{~km}^{2}$ found approximately $50 \%$ higher biomass productivity comparing one and five species plots (Gamfeldt et al., 2013). Also a large-scale cross-European modelling study indicated that tree wood productivity was positively related to species richness (Vilà et al., 2013).

However, mainly due to the longer life cycle of trees, and possible changes in biodiversity-productivity relationships with tree age, experimental approaches in forests remain complicated (Pretzsch and Schütze, 2009). Pretzsch (2005) reported that productivity of mixtures of Norway spruce (Picea abies) and European beech (Fagus sylvatica) trees may differ from the respective monocultures by -20 to $10 \%$, dependent on site conditions. In addition climatic variables influenced wood production in varying direction and magnitude dependent on forest type (Vilà et al., 2013). Even a weak negative relationship between tree species diversity and above-ground biomass was found on several sites across Central European forests (Szwagrzyk and Gazda, 2007) and also at our study site (Jacob et al., 2010).

In grasslands, it has been observed that plant species diversity enhances transpiration rates (Verheyen et al., 2008). In addition, in an experimental tree plantation in Panama, transpiration increased with increasing tree species diversity (Kunert et al., 2012). In both studies, complementarity of water uptake was discussed as an underlying mechanism. This would imply water resource partitioning and, consequently, more effective utilization of water resources (Hagger and Ewel, 1997; Hooper et al., 2005). Hence, biodiversity-rich stands may be more susceptible to drought events since they extract water "more efficiently" than less diverse stands. This coherence has already been demonstrated for grasslands (Van Peer et al., 2004; Verheyen et al., 2008).

It is important to study if a water-use-diversity relationship also exists for forests, since there is an ongoing trend in Central European silviculture towards more naturalness or close-to-nature forestry (O'Hara, 2001), which implies a transformation of monocultural stands of narrow tree diameter range into stands composed of several tree species with a broader range of diameters. In addition to improving ecological, commercial and recreational purposes of forests, it is believed that this forest transformation might increase the resilience to extreme climatic conditions (LÖWE, 2011). Climatic extremes are predicted to occur more frequently for large parts of Central Europe (Rowell and Jones, 2006; Christensen et al., 2007). Now if the results from grasslands are valid for forests too, the anticipated effect of forest restructuring might not be achieved.

First studies on the relationship between tree species diversity and forest water use were carried out in the broadleaved Hainich forest in Germany: here increased water extraction from the topsoil during a summer drought in diverse plots compared to Fagus-sylvatica-dominated plots was observed (Krämer and Hölscher, 2010). Canopy transpiration was also found to differ among diverse and less diverse stands in certain years (Gebauer et al., 2012). However, none of the outcomes could clearly be attributed to a biodiversity effect, as increasing biodiversity was paralleled by decreasing $\mathrm{Fa}$ gus admixture, and no monocultures of any other species involved were studied. In order to differentiate between the effects of tree diversity and of species identity, we applied a new experimental design in the same study area, where all observed tree species occur in monospecific study plots and in admixture. We selected 100 groups of three neighbouring trees, hereafter named tree clusters, which contained all possible combinations of five tree species (Acer pseudoplatanus, Carpinus betulus, Fagus sylvatica, Fraxinus excelsior, and Tilia sp.). All species occurred in single-species clusters $(n=20)$, as well as in two- and three-species mixtures ( $n=40$, each). We asked whether stand water use is related to tree diversity. Our hypothesis was that water uptake in tree clusters increases with increasing species diversity.

\section{Methods}

\subsection{Study area}

The study was conducted in the deciduous Hainich forest in central Germany close to the village of Weberstedt $\left(51^{\circ} 05^{\prime} 28^{\prime \prime} \mathrm{N}, 10^{\circ} 31^{\prime} 24^{\prime \prime} \mathrm{E}\right)$. The forest has remained free from harvesting or thinning for almost $50 \mathrm{yr}$, and it was estimated that the area has hosted a deciduous forest for over 200 yr (Mölder, 2009; Mölder et al., 2006). The study sites are located on level terrain in the south-eastern part of the forest area (Fig. 1a) at an elevation of approximately $350 \mathrm{~m}$ a.s.l. The park receives a mean annual precipitation of 544-662 mm (average of $30 \mathrm{yr}$ of precipitation records from four climate stations around the national park; DWD, 2008) and has a mean temperature of $7.5^{\circ} \mathrm{C}$. Soil texture is characterized by high clay content of $\sim 25 \%$ at a soil depth of 0 $0.3 \mathrm{~m}$ and $33-41 \%$ at $0.4-0.6 \mathrm{~m}$, respectively (Guckland et al., 2009). Limestone already occurred at shallow soil depths $(0.6-1.0 \mathrm{~m})$ limiting the rooted soil volumes. Stand fine root biomass in the area decreased exponentially with soil depth with $63-77 \%$ being concentrated in the upper $20 \mathrm{~cm}$ (Meinen et al., 2009).

In 2008, tree clusters were selected in two mixed forest stands within the Hainich forest area (sub-areas Lindig and Thiemsburg, Fig. 1b). All clusters were located in close vicinity to the study plots of Krämer and Hölscher (2009, 2010). Each cluster consisted of three co-dominant trees arranged in a triangular shape with their surrounding neighbours. Observed tree species on these clusters were Acer pseudoplatanus (sycamore maple), Carpinus betulus (hornbeam), Fagus sylvatica (European beech), Fraxinus excelsior (ash) and Tilia sp. (lime). In this forest, the two Tilia species cordata and platyphyllos often form hybrids, which are phenotypically difficult to differentiate. Hence we did not differentiate at the species level, and we refer to them as Tilia sp. 


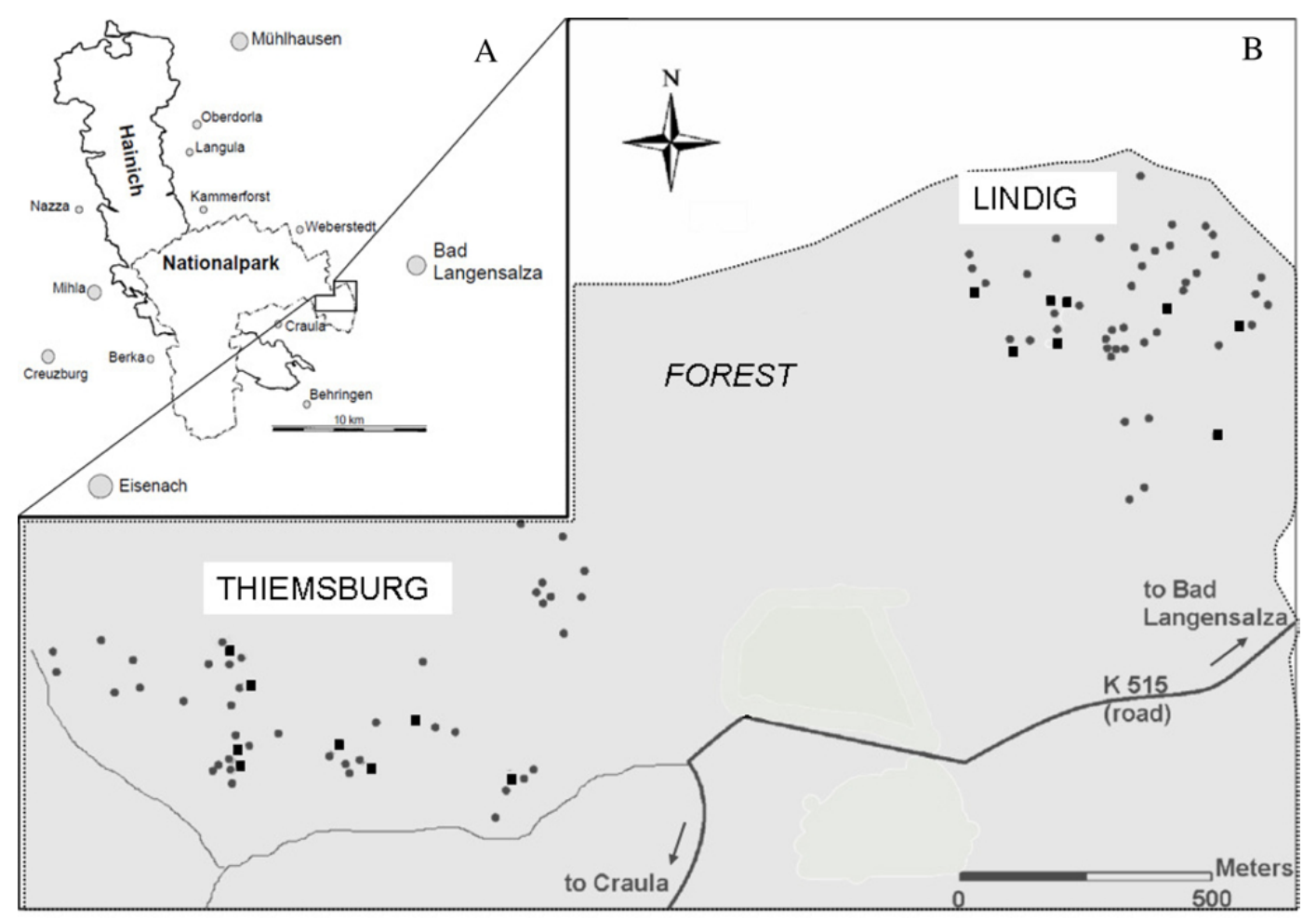

Figure 1. Location of the 100 tree clusters in the two forest areas. The grey dots and black rectangles indicate cluster positions. The 16 black rectangles represent intensively measured clusters (figure based on Seidel, 2011).

Table 1. Soil properties ( $0-0.3 \mathrm{~m}$ soil depth) and structural characteristics of the one- to three-species tree clusters (means \pm sd). Similar letters indicate no significant differences between the three diversity levels ( $p \leq 0.05$, ANOVA and Tukey's HSD or Kruskal-Wallis test, canopy openness).

\begin{tabular}{llll}
\hline Cluster characteristics & & $\begin{array}{l}\text { Diversity level } \\
\text { 2-species }(n=40)\end{array}$ & 3-species $(n=40)$ \\
\hline Canopy openness $(\%)$ & $10.7 \pm 5.6 \mathrm{a}$ & $9.6 \pm 5.6 \mathrm{a}$ & $9.0 \pm 2.5 \mathrm{a}$ \\
Diameter at breast height $(\mathrm{m})$ & $0.43 \pm 0.11 \mathrm{a}$ & $0.43 \pm 0.08 \mathrm{a}$ & $0.45 \pm 0.07 \mathrm{a}$ \\
Cluster area $\left(\mathrm{m}^{2}\right)$ & $25.2 \pm 17.9 \mathrm{a}$ & $23.3 \pm 13.4 \mathrm{a}$ & $23.8 \pm 15.1 \mathrm{a}$ \\
Soil bulk density $\left(\mathrm{g} \mathrm{cm}^{-3}\right)$ & $1.18 \pm 0.08 \mathrm{a}$ & $1.21 \pm 0.09 \mathrm{a}$ & $1.19 \pm 0.09 \mathrm{a}$ \\
Soil clay content $(\%)$ & $28 \pm 4 \mathrm{a}$ & $27 \pm 5 \mathrm{a}$ & $28 \pm 7 \mathrm{a}$ \\
\hline
\end{tabular}

Cluster selection was based on a predetermined combination of tree species comprising all possible neighbourhood combinations of the five tree species. This resulted in five different single-species, ten two-species and ten three-species cluster combinations, with each combination being replicated four times (twice replicated in each sub-area, Thiemsburg and Lindig). In the two species combinations, it was assured that not one species dominated the mixture in all four replicates. From the 100 clusters, we selected a subset of 16 clusters containing the species Fagus sylvatica, Tilia sp. and Fraxinus excelsior in monoculture and in three-species clusters. The selected clusters were used to monitor soil water content in the subsoil, to increase the temporal resolution of soil water content measurements and to conduct throughfall measurements (Fig. 1b).

Since the clusters of the two forest sub-areas were statistically not different with regard to soil properties and tree structural characteristics, they were pooled in the subsequent analysis. Soil and stand structural characteristics, such as soil bulk density $\left(\mathrm{g} \mathrm{cm}^{-3}\right)$, clay content $(\%)$, tree diameter at breast height (dbh in $\mathrm{m}$ ), cluster ground area $\left(\mathrm{m}^{2}\right)$ and openness $(\%)$, were also not significantly different among diversity levels (Table 1). 


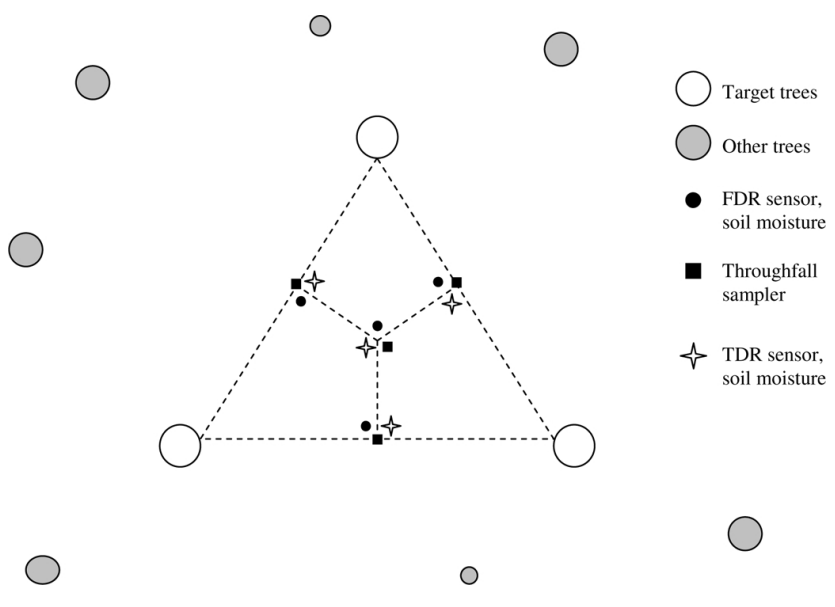

Figure 2. Schematic study plot design (tree cluster) with locations of FDR, TDR sensors and throughfall samplers.

\subsection{Meteorological data, soil water content and throughfall measurements}

Data on air temperature $\left(\mathrm{C}^{\circ}\right)$, gross precipitation $(\mathrm{Pg}, \mathrm{mm})$, global radiation $\left(\mathrm{MJ} \mathrm{m}^{-2} \mathrm{day}^{-1}\right)$ and wind speed $\left(\mathrm{m} \mathrm{s}^{-1}\right)$ were recorded hourly at the meteorological station Weberstedt (Meteomedia, Germany), 2-3 km northwest of our study area at an altitude of $270 \mathrm{~m}$ a.s.l. On all 100 clusters we conducted measurements of soil volumetric water content $\left(\theta\right.$ in $\left.\mathrm{m}^{3} \mathrm{~m}^{-3}\right)$ at four points with a time domain reflectometer (TDR) probe (CS616, Campbell Scientific) at a depth of 0-0.3 m. Water content was assessed monthly throughout the vegetation period in 2009 (30 April to 31 October) and on four occasions during a dry spell in summer (30 July, 10 and 24 August, 1 September).

The 16 intensive clusters were equipped with PVC access tubes, enabling measurement of $\theta$ with a portable frequency domain reflectometry (FDR) sensor (Diviner 2000, Sentek Pty Ltd. Stepney, Australia) in addition to the TDR measurements. Access tubes were installed to a maximum depth of $0.7 \mathrm{~m}$ in which sensor readings were taken at depth intervals of $0.1 \mathrm{~m}$. Volumetric soil water content was measured weekly throughout the vegetation period. The FDR sensor had already been soil- and depth-specifically calibrated for the local soil conditions in the field (Krämer and Hölscher, 2010). By correlating 72 FDR readings at different soil water contents with corresponding TDR readings in the direct vicinity of the FDR, we established a site-specific calibration for the TDR probes.

Throughfall was monitored weekly throughout the whole vegetation period on the 16 clusters with rainfall collectors consisting of a plastic bottle screwed to a funnel attached to a metal rod at a height of $1 \mathrm{~m}$. To reduce evaporation from the rain gauge, a table tennis ball was placed in the funnel. The instrumental set-up within a tree cluster is shown in Fig. 2.

\subsection{Soil water budgeting}

Daily water uptake, $W u\left(\mathrm{~mm} \mathrm{day}^{-1}\right)$, between two consecutive measurements of soil water content was calculated by Eq. (1):

$W u=\frac{(T f+S f)-\Delta S}{\Delta t}$,

where $T f$ is throughfall ( $\mathrm{mm}), S f$ stemflow ( $\mathrm{mm}), \Delta S$ change in soil water storage between two successional measurements $(\mathrm{mm})$ and $\Delta t$ the elapsed time between the two successional measurements (days). $\Delta S$ ( $\mathrm{mm}$ ) was calculated for each cluster from $\theta\left(\mathrm{m}^{3} \mathrm{~m}^{-3}\right)$, measured by TDR sensors, multiplied by the depth of the soil layer in which $\theta$ was measured and converted to $\mathrm{mm}$.

Tf was either measured directly (16 cluster subset) or calculated from an established relationship with average cluster $\mathrm{dbh}(T f=81.7-0.2 \mathrm{dbh})$ for the remaining clusters. $S f$ for each rainfall event during our study period was estimated from findings of an earlier study in the same area using 50 stemflow collectors on all five tree species during two successive years (Krämer and Hölscher, 2009). The magnitude of $S f$ in the Hainich forest in general is usually relatively low ( $\sim 0.4$ to $6.3 \%$ of $P g$ ), varying more between seasons than between plots of differing tree species diversity/Fagus admixture. It was highest on Fagus trees of large dbh and during high rainfall events, but even then stemflow was lower compared to other Fagus-dominated forests (Krämer and Hölscher, 2009). We quantified intensity and duration of single rainfall events from hourly data on gross precipitation automatically recorded at the nearby weather station. We then calculated $S f$ for given rainfall intensities for each of our cluster trees, dependent on tree species and dbh based on raw data from the study of Krämer and Hölscher (2009). For $\mathrm{Fa}$ gus and Carpinus, $S f$ was calculated as $1 \%$ of gross precipitation for trees with $\mathrm{dbh}>10$ and $<30 \mathrm{~cm}$; for trees $>30 \mathrm{~cm}$ Sf was $3 \%$ at rainfall intensities $>2.0$ and $<6.0 \mathrm{~mm} \mathrm{~h}^{-1}$. For Acer, Fraxinus and Tilia, $0.5 \%$ of $P g$ was added to the water budget for trees with $\mathrm{dbh}>30 \mathrm{~cm}$, at rainfall intensities $>4 \mathrm{~mm} \mathrm{~h}^{-1}$. All incoming water ( $T f$ and $S f$ ) is regarded to infiltrate the soil. Hence evaporation from understorey vegetation and litter layer enters the budget as root water uptake.

Water use of all 100 clusters was only calculated during the dry spell for the soil layer in which the TDR was inserted $\left(0.3 \mathrm{~m}\right.$ in depth; hereafter referred to as $\left.W u_{30 \mathrm{~d}}\right)$. With regard to the 16 cluster subsets on which water content was additionally measured down to $0.7 \mathrm{~m}$ by FDR sensors, $W u$ was determined for all $0.1 \mathrm{~m}$ wide subsections of soil according to Eq. (1) and then summed to yield $W u_{70}$. Average water use measured on the 16 clusters during the dry spell is referred to as $W u_{70 d} . W u_{70}$ was determined on several occasions during the vegetation period only where trees were fully in leaf. Drainage or surface runoff could be neglected here (Bittner et al., 2010 and personal communication with the author, 2010). Also the soil parameters (high residual water content and low 
saturated hydraulic conductivity in the subsoil) lead to very slow water movement rates (Bittner et al., 2010) from which we gain further confidence in our no-drainage assumption.

\subsection{Statistical analysis}

All statistical analyses were done with $\mathrm{R}$ version 3.0.0 ( $\mathrm{R}$ Core Team, 2012). We fitted linear mixed effect models (LME, lme4 package) using maximum likelihood estimation (MLE) to determine the influence of the 25 possible species combinations, the 3 diversity levels or absence/presence of the 5 species (set as fixed effects respectively). For the analysis of $W u_{30 \mathrm{~d}}$, the sub-areas (Tiemsburg/Lindig) served as a random effect. We included the covariates cluster area and cluster dbh and, in the case of the three-diversity-level model, also their interactions, since they are likely to influence cluster water use.

Another LME was used to judge the influence of the four possible species combinations (Fagus, Tilia, Fraxinus and their mixture), dbh and area on $W u_{70}$ with the date of measurement $(n=11)$ as a random effect. To ensure homoscedasticity, $W_{70}$ was log-transformed here. $W u_{70}$ was further modelled as a smoothing function of radiation and the factor species combination with generalized additive models (GAMs, mgcv package) employing thin plate regression splines. The model was supplied with weights $\left(W u_{70}^{-1}\right)$ to ensure homoscedasticity. Model comparison and the assessment of the significance of the smoothers and the factor species combination within a model were done with $F$ tests.

Residuals of all models were visually checked for homoscedasticity and normality by box plots, residuals against fitted values plots and Q-Q plots. Non-significant effects $(p>0.05)$ in LMEs were discarded from the full model stepwise by comparing models with the same random effect structure fitted with MLE. To this end, likelihood ratio tests were used, since both $t$ statistic provided by "anova (LME)" and $F$ statistic provided by "summary (LME)" are only approximate (Zuur et al., 2009). Differences between species combinations or diversity levels, whenever significant in the mixed model, were further investigated using Tukey's HSD post hoc tests (glht, multcomp package).

The relationship between $T f$ and dbh was determined using a linear regression model. Differences in soil properties and structural characteristics among the three diversity levels were assessed with ANOVA or Kruskal-Wallis tests. We further used Spearman's rank correlation analysis to relate selected stand structural variables and $W u_{30 d}$ on all 100 clusters. All statistical tests were considered significant where $p \leq 0.01$ and marginally significant where $p \leq 0.05$.

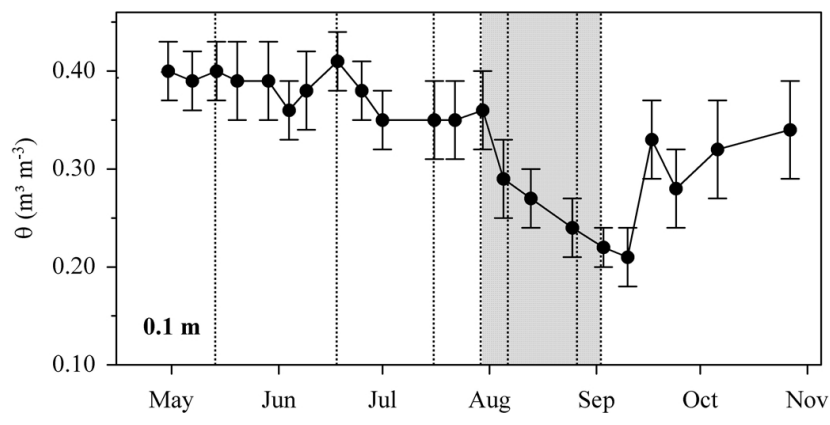

Figure 3. Average volumetric soil water content (FDR sensor) at $0.1 \mathrm{~m}$ soil depth during the study period in 2009 . Values are means $\pm \mathrm{sd}$ ( $n=16$ clusters). Dotted lines indicate the occasions where $\theta$ was measured on all 100 clusters with TDRs; the shaded area represents the dry spell (three subsequent measurement intervals) for which $W u_{30 \mathrm{~d}}$ and $W u_{70 \mathrm{~d}}$ were determined.

\section{Results}

\subsection{Meteorological conditions}

Rainfall in 2009 totalled $773 \mathrm{~mm}$, which was higher than the long-term average rainfall measured at four stations around the park $\left(544-662 \mathrm{~mm} \mathrm{yr}^{-1}\right)$. This is mainly attributed to two heavy storms in July. The rather wet July was followed by an August of below-average rainfall, the month on which we mainly focused our study. Here, the average maximum and minimum air temperatures were about $25^{\circ} \mathrm{C}$ and $12^{\circ} \mathrm{C}$, respectively. The global radiation average was $17.5 \mathrm{MJ} \mathrm{m}^{-2}$ day $^{-1}$. During the dry spell, $P g$ was about $9 \mathrm{~mm}$ per week.

\subsection{Soil water content}

Throughout May and June 2009, volumetric soil water content averaged over the 16 intensively studied clusters was continuously high at around $0.40 \mathrm{~m}^{3} \mathrm{~m}^{-3}$ (Fig. 3). Two storms at the end of July were not found to notably increase soil water content. Thus, we assume that drainage or overland flow could have possibly occurred here, and therefore we did not include these occasions in the calculations of $W u_{70}$. In a following period of low rainfall, soil water content decreased continuously from the end of July through to the beginning of September. For this dry spell, soil water budgeting was conducted on both the 16 intensive and the 100 cluster groups (see Fig. 1) yielding $W u_{70 d}$ and $W u_{30 d}$.

\subsection{Soil water budget -16 clusters}

Average $W u_{70}$ ( $n=16$ clusters) calculated for all occasions within the vegetation period (trees fully in leaf) ranged overall between 0.8 and $4.0 \mathrm{~mm} \mathrm{day}^{-1}$ (Fagus 1.2-4.0; Tilia 0.93.8; Fraxinus $1.3-3.9$ and mix $0.8-3.1 \mathrm{~mm} \mathrm{day}^{-1}$ ) and was closely related to average daily global radiation $(R g)$ during these occasions. For illustration simple linear regression 


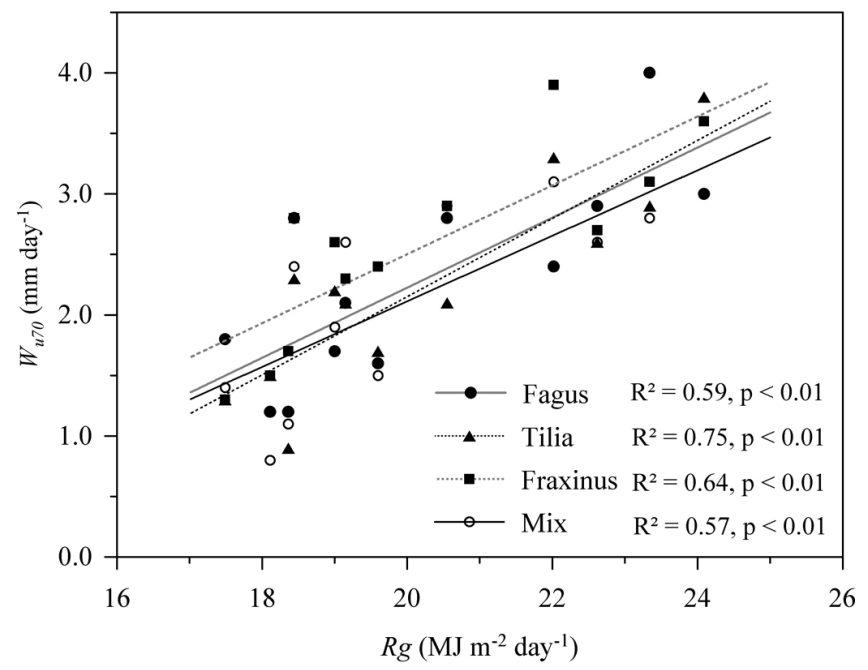

Figure 4. Average $W u_{70}$ as a function of daily global radiation $(R g)$ for 4 different species combinations $(n=4$ per species combination). Shown are data of 11 measurement occasions from June to mid-September 2009 when trees were fully foliated and linear regression models between average $W u_{70}$ and radiation.

models are given for all species combinations (Fig. 4). Modelling $W u_{70}$ as a smoothing function of $R g$ and species combination (levels: Fagus, Tilia, Fraxinus and mix) with a GAM revealed a highly significant smoothing term $(F=$ $16.21, p<0.001)$ but no effect of the factor species combination $(F=2.38, p=0.07)$. A model with a species-specific smoothing term was not significantly different from a model with one smoothing term for all species.

Comparing a full MLE (explanatory variables: species combination, dbh and area and all two-way interactions) with MLEs with selectively dropped two-way interactions indicated no significant two-way interactions. Dropping species, dbh or area selectively from a new full MLE fitted without interaction terms indicated no effect of either one of these variables on $W u_{70}$. However, having a full model with species as only an explanatory variable and comparing it to a model including only random effects revealed that species had slight effects on $W u_{70}(L$ ratio $=9.07, p=0.03)$. Tukey's HSD post hoc tests showed that monospecific Fraxinus clusters had higher water use (average of 11 measurement occasions $=0.35 \mathrm{~mm}^{-1 a y^{-1}}$ ) compared to the mixed species clusters $(t=-2.67, p=0.04)$. Neither Fraxinus nor mixed clusters were any different from the other species combinations.

The measured throughfall component of $W u_{70}$ was not related to the species composition or diversity throughout the measurement occasions in the year 2009. The same result was found during the dry spell (30 July-1 September 2009), where average $T f$ was low $(32 \pm 9.5 \mathrm{~mm})$ ranging between 62 and $80 \%$ of $P g$. Tf during the dry spell however declined with increasing average dbh of each cluster (Fig. 5). Therefore we used this relationship to calculate $T f$ for all

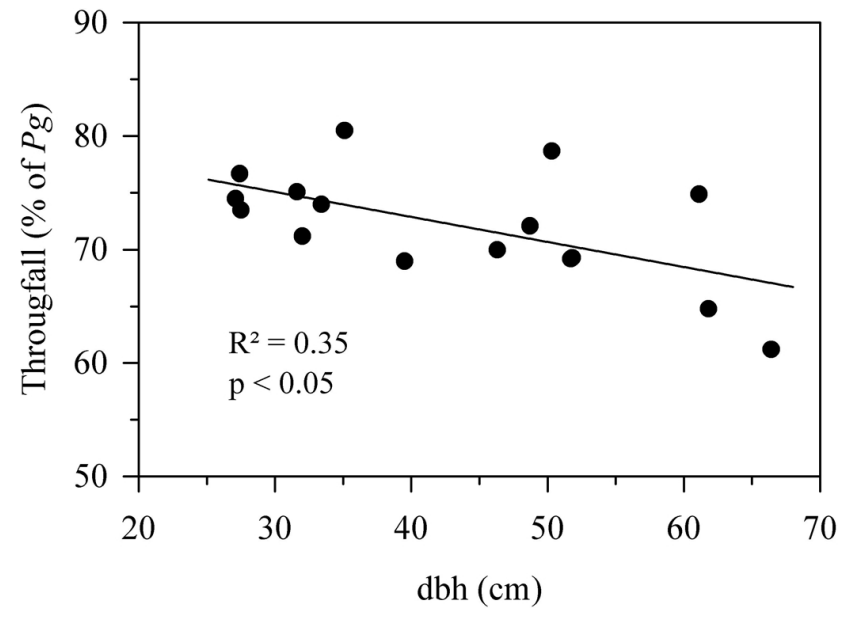

Figure 5. Relationship between average throughfall (\% of gross precipitation, $P g$ ) and average cluster dbh during the soil desiccation period (30 July to 1 September 2009). The equation reads Tf $=81.7-0.2 \mathrm{dbh}$.

100 clusters here. Estimated $S f$ input on the clusters was $0.3 \pm 0.25 \mathrm{~mm}$ during the whole desiccation period and played therefore only a marginal role.

\subsection{Soil water budget - 100 clusters}

The 25 possible species combinations, cluster dbh and cluster area had no influence on $W u_{30 d}$. An LME with species combination as the only explanatory variable was not different from a model with only random effects $(L$ ratio $=3.96$, $p=0.14$; Fig. 6). Likewise, testing for presence or absence of the 5 species resulted in no effect on daily water uptake. A similar picture was found when $W u_{30 d}$ of the 100 tree clusters was grouped according to diversity levels (Fig. 7): LMEs showed no significant main or interaction effect of the explanatory variables on $W_{30}$. As there were three subsequent measurement intervals throughout the dry spell (Fig. 3), we also calculated water uptake for each interval. Mean water uptake across all clusters was $2.2 \pm 0.7$ for 30 July-6 August, $1.9 \pm 0.2$ for $6-24$ August, and $1.6 \pm 0.7 \mathrm{~mm} \mathrm{day}^{-1}$ for 24 August-1 September. Again, no significant differences between tree species combinations or diversity levels were found employing an LME with date of measurement as a random effect.

Further correlation tests between $W u_{30 \mathrm{~d}}$ and selected stand structural variables from all 100 clusters showed only a slight correlation between bulk density and water use (Table 2). Still, certain stand characteristics correlated with cluster area. Average dbh as well as canopy openness increased with increasing ground area of the clusters $(r=0.39, p<0.01$ and $r=0.25, p=0.01$ ). 


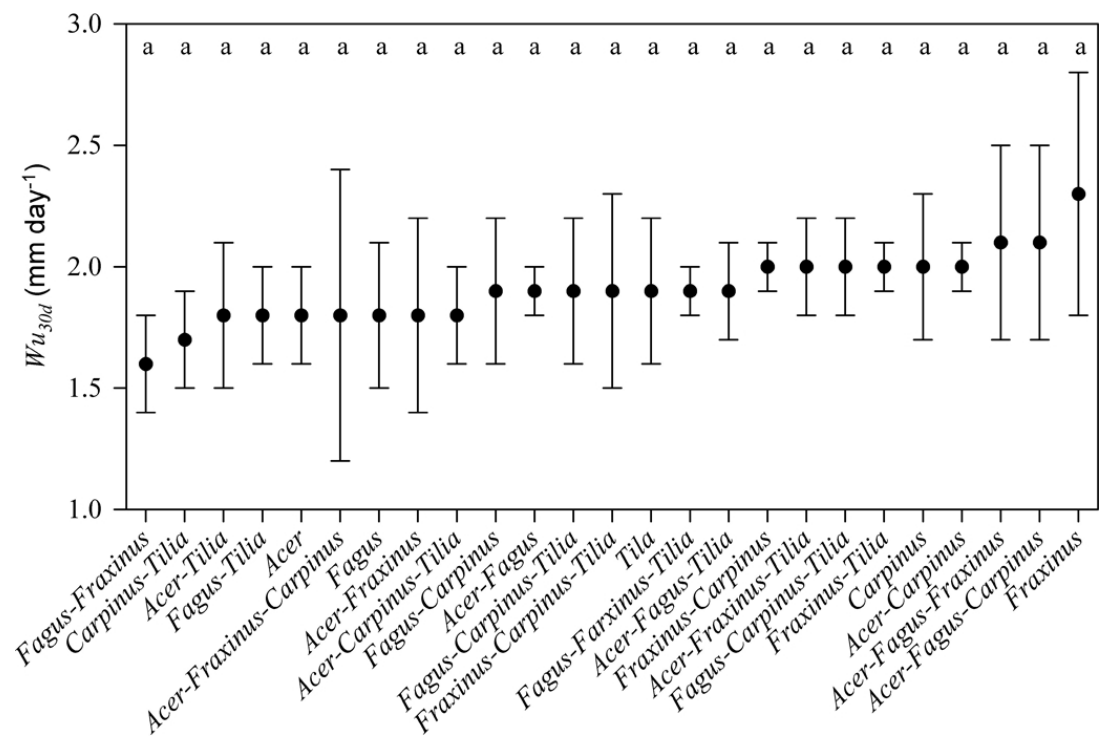

Figure 6. $W u_{30 \mathrm{~d}}$ for all possible species combinations of Fagus, Tilia, Fraxinus, Acer and Carpinus during the soil desiccation period from 30 July to 1 September 2009. Values are means $\pm \operatorname{sd}(n=4)$; same letters specify no significant difference between species (LME and Tukey's HSD).

Table 2. Relationship between $W u_{30 \mathrm{~d}}$ during soil desiccation period from 30 July to 1 September 2009 and selected stand structural variables on the clusters. All 100 clusters were included in the analysis (Spearman's rank correlation).

\begin{tabular}{lrc}
\hline Variable & $r$ & $p$ \\
\hline Canopy openness (\%) & -0.18 & 0.08 \\
Bulk density $\left(\mathrm{g} \mathrm{cm}^{-3}\right)$ & -0.21 & 0.04 \\
Clay content $(\%)$ & 0.17 & 0.09 \\
Cluster area $\left(\mathrm{m}^{2}\right)$ & -0.18 & 0.08 \\
Mean dbh of cluster trees $(\mathrm{cm})$ & -0.18 & 0.08 \\
\hline
\end{tabular}

\section{Discussion}

\subsection{The approach}

The temporal frequency of measurements in hydrological studies is often very high considering that data can be logged automatically at almost any desired rate. At the same time, it is barely possible to establish a similar level of measurement replication on a broader spatial scale due to restrictive costs for instrumentation or logistical issues. As a result, the number of spatial replicates is often disproportionate to the frequency of sampling, and it is questionable whether such data can be spatially representative. With our 100-cluster approach and 400 measurement points overall, we tried to compensate for the lack of spatial resolution at the cost of a finer temporal resolution. However, a subset of 16 intensive clusters, for which data were gathered more frequently, served to support the 100-cluster approach. During cluster selection, care was taken to ensure clusters were as homogenous as possible in terms of ground area, soil physical properties, tree height, dbh, and terrain inclination. As such, it was not a randomized selection. Moreover, there is still uncertainty around how one can account for stemflow values in water budget calculations, as there is no understanding on how stemflow water distributes through the soil. In our approach, measurement devices were arranged along the median line between each tree pair and in the cluster centre, which made it possible for stemflow water not to be measured where the distance from the device to the next respective stem was too far. However, as we concentrated our measurements on a period of soil water desiccation with low rainfall, the water budget was only very marginally affected by stemflow anyway.

An analysis of the relative fine root contribution at $0-0.2 \mathrm{~m}$ also showed that below-ground cluster space was not exclusively occupied by roots of tree species forming the respective cluster but also by neighbouring trees outside the cluster (Jacob et al., 2013, supplemental data). However, across all clusters the target tree species contributed $84.2 \pm 10.2 \%$ to the standing fine root biomass. Single-species clusters of Carpinus and three-species clusters including Fagus and Carpinus appeared to be more affected by root space occupation of non-cluster trees compared to other species. In addition, the fine root biomass on two- and three-species clusters was not always homogenously distributed among the cluster forming tree species. As such, the identification of possible species identity effects on soil water uptake was further complicated. We nonetheless assume that our high number of spatial replicates, which is quite unusual in ecohydrological studies, represents a special advantage of this design over others and that it may be very helpful in unravelling possible effects of 


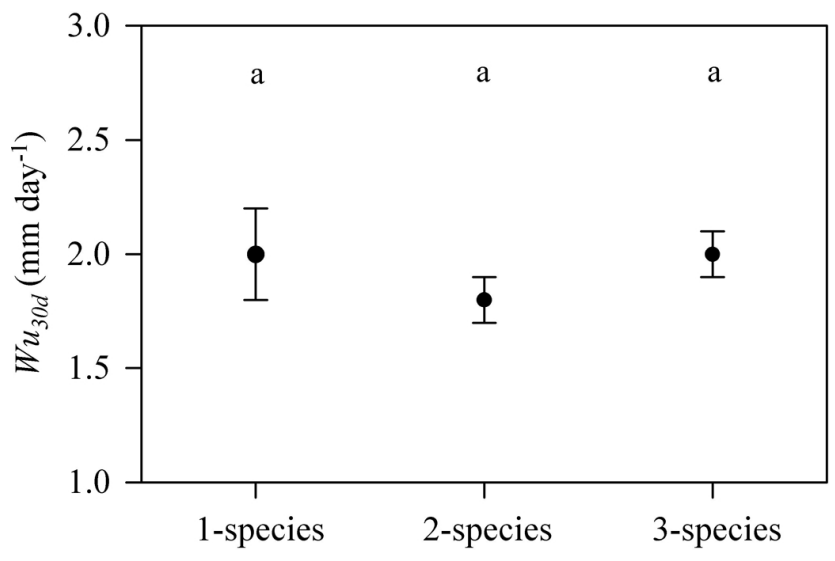

Figure 7. $W u_{30 \mathrm{~d}}$ grouped for the three diversity levels during the soil desiccation period from 30 July to 1 September 2009. Values are means \pm sd (1-species: $n=20 ; 2$-, 3-species: $n=40)$; same letters specify no significant difference between species (LME and Tukey's HSD).

species composition and diversity. Additionally, the strong relationship between cluster water use and global radiation gave us confidence in the data.

\subsection{Throughfall and stemflow}

Throughfall as the main input of water to the system under consideration was not related to species identity in the 16 clusters, nor did the mixed clusters differ from the monocultures. In addition, stand structural parameters only explained Tf during some measurement occasions (e.g. average cluster dbh explained $T f$ during the dry spell). This finding may have several reasons: first of all, we set up our experiment to test for effects of differing diversity levels or species combinations. Thus, clusters were selected to minimize variations in ground area, tree size and tree age, etc., and a lack of correlation between tree or stand structural variables and $T f$ was expected. Secondly, $T f$ is not only driven by tree architecture (leaf inclination, nature of the bark, branch angle) but also by stand structural characteristics such as stand height, crown length, and canopy roughness (Krämer and Hölscher, 2009). Consequently, it is expected that these parameters influence rainfall partitioning at a much larger scale than on the rather small tree clusters. All our study clusters were embedded in a larger mixed forest stand, and possible differences between single- and mixed-species stands could only have been detected at a larger scale. However, respective large-scale monocultures of all tree species are not likely to be found in unmanaged mixed forests of advanced age. Thirdly, climatic conditions such as rainfall intensity and duration, wind and relative humidity which affect $T f$ (Crockford and Richardson, 2000) might additionally work unequally on diverging species. Therefore it depends very much on the nature of the respective rainfall event or the season under consideration if a diversity or species identity effect is detectable (Krämer and Hölscher, 2009). Fourthly, 3-D laser scans on the clusters showed that canopy space exploration, which is highly influential on throughfall, was not influenced by species diversity (Seidel et al., 2013). However, denser canopy crowns were found where Fagus was present, which might also partly explain why Krämer and Hölscher (2009) found decreasing Tf with increasing proportion of Fagus trees present for some of their measurement occasions. However, none of the relationships between $T f$ and tree diversity, proportions of tree species present or stand characteristics established by them at our research site were stable during different seasons or over years. Indeed, their measured $T f$ correlated with tree diversity only for half of the seasons for which data were gathered.

Hence, we conclude that a clear relationship between $T f$ and tree diversity and $T f$ and species identity or other parameters could not be found at our site. This implies that the relationship found for dbh and $T f$ during the dry spell should only be taken as an aid to transfer $T f$ measured in a certain period from the 16 clusters to the 100-cluster approach and not as a general rule for the given stand. The second input to our system, stemflow, is of small magnitude compared to the water input to the soil via throughfall and, as our focus was on the dry spell during which precipitation was generally low, $W u_{30 \mathrm{~d}}$ was only marginally influenced by $S f$. In summary, the water inputs to the soil were not driven by tree diversity or species identity in our study.

\subsection{Soil water uptake}

Measured $W u_{70 d}$ (dry spell) on the 16 clusters ranged from about 2.6 to $3.5 \mathrm{~mm} \mathrm{day}^{-1}$ and was higher compared to values obtained for the plots with differing diversity levels at our research site based on sap flux estimates for the years 2005 and 2006 (1.1 to $2.5 \mathrm{~mm} \mathrm{day}^{-1}$; Gebauer et al., 2012). However, in contrast to our method, sap flux studies do not account for understorey transpiration, evaporation from the topsoil and transpiration of trees with dbh below $10 \mathrm{~cm}$ (Gebauer et al., 2012). In addition, a species-specific calibration for Fraxinus (Herbst et al., 2007) was not applied by Gebauer et al. (2012) which leads to an underestimation of water use by Fraxinus trees and thus to an overall lower water use of plots with strong Fraxinus presence.

Calculated amounts of daily soil water uptake for the whole period from 30 July to 1 September agree well with model calculations for the adjacent plots of differing diversity levels in Hainich forest (Bittner et al., 2010). We also found positive relationships between the calculated volume of daily water uptake of the 16 clusters throughout the season and the average daily global radiation during the respective measurement intervals (Fig. 4), giving us further confidence in the applied water uptake calculation.

Our data did not indicate an influence of species diversity (Fig. 7), nor of species composition (Fig. 6) on $W u_{30 \mathrm{~d}}$ of the 
100 clusters during the dry spell. Further, cluster dbh and area or the presence of any certain species had no effect on water use. Recognizing that the input of water $(T f, S f)$ was alike for all diversity levels, water uptake by roots per unit soil volume must also have been similar. However, this result is in contrast to findings obtained in monocultures and two-, three- and five-species mixtures in a Panamanian tree plantation (Kunert et al., 2012) and in advanced forest plots of two species and their mixture (Schume et al., 2004). We also tested for possible effects of the wider neighbourhood on calculated water uptake on the clusters. Thus, Shannon biodiversity index was determined for a $20 \mathrm{~m}$ radius surrounding the centre point of each cluster (Seidel et al., 2013) and correlated with water uptake. As no significant relationship was found (data not shown), we are confident that the ascertained findings remain similar even at a wider spatial resolution.

However, in Fig. 6 it can be seen that water use of Fraxinus monocultures during the dry spell was at the upper end of the range of water use rates measured. Also the analysis of the 16 clusters that were monitored intensively in time showed that the water use of Fraxinus was about $0.35 \mathrm{~mm} \mathrm{day}^{-1}$ higher compared to the mixture (marginally significant), but not significantly different from Fagus and Tilia clusters. But since the degrees of freedom used in the calculation of Tukey's tests can only be approximated for LMEs (see also Bates, 2006) and given the fact that the differences found are only marginally below our significance level of $p=0.05$, this statement should be interpreted with care. Since we did not find any other indication for a diverging water uptake of mixtures compared to monocultures, we suppose that the difference between Fraxinus and mixed clusters is based on Fraxinus properties rather than on specific properties of the mixture. Indeed, Fraxinus differs in many characteristics from other tree species. Herbst et al. (2007) mention a considerably higher magnitude of sap flux densities of Fraxinus, compared to diffuse-porous species with calibrated sap flux sensors. Also a higher transpiration per unit leaf area of Fraxinus was reported for our area (Hölscher et al., 2005). But the higher water use could also result from the water use of the undergrowth in Fraxinus clusters.

It is somewhat remarkable that the water use of the monospecific plots only differed marginally from one another (slightly higher water use of Fraxinus clusters), since many authors found strongly differing hydraulic parameters and sap flux densities for the trees grown at our site (Hölscher et al., 2005; Gebauer et al., 2008; Köcher et al., 2009). Moreover, trees in our 16 clusters were shown to take up water from different soil depths when tree species were mixed and varied in dbh (Meißner et al., 2012), despite the lack of vertical fine root stratification among the species under consideration from the Hainich forest (Meinen et al., 2009). These findings lead to the assumption that if a species-dependent water use of trees as supported by physiological measurements exists, the spatial arrangement of different species might override such an effect (in particular below ground) and yield similar water uptake per unit soil volume among the monospecific plots and the diversity levels of the clusters. This balancing effect could not be found in the Panamanian plantation (Kunert et al., 2012), since this plantation was newly established (7 yr old) and arranged in regular planting schemes.

The same would be valid if, in contrast to species identity, simple size effects of trees governed their water use ("functional convergence"), which means that large trees should use more water than smaller ones, irrespective of species identity (Meinzer et al., 2005). This implies that large trees, having a higher water use per individual, must occupy more ground area compared to smaller ones if the water uptake per unit soil volume is not affected by the size of cluster trees. In our clusters we found a positive correlation between average cluster dbh and cluster area $\left(R_{a d j}^{2}=0.3 ; p \leq 0.01\right)$, which could indicate the latter. Likewise, there was a positive correlation between canopy openness and cluster area, which could additionally lead to higher amounts of throughfall input on large clusters. Krämer and Hölscher (2009) found a relationship between canopy gap fraction and $T f(r=0.74)$ in one out of three seasons for which gap fraction was determined. In our short measurement period, however, this could not be found.

Furthermore, it was stated that the understorey in forests can effectively buffer differences in tree canopy transpiration (Roberts, 1983). Since both cover and species richness of the herb layer increased with tree diversity in our clusters (Vockenhuber et al., 2011), it is likely that some sort of feedback between herb and tree layer exists. Still there is much uncertainty in the estimation of the contribution of understorey (evapo-)transpiration to the overall cluster water use because the density of herb layer cover varies during the vegetation period and, under prolonged desiccation, herb layer cover is diminished, because most herbaceous plants are droughtsensitive. Moreover, the thickness of the litter layer was negatively related to tree species diversity/decreasing Fagus abundance in our area (Mölder et al., 2008). A thick litter layer would intercept much of the throughfall but prevent water from evaporating from the soil and suppress competition for water by the undergrowth. A closed herb layer on the other hand would intercept rainfall as well, but it would also transpire water taken up from the soil.

Nevertheless, the effects of (evapo-)transpiration differences between different trees of a cluster and among trees and the cluster understorey might cancel each other out. In basic terms, in mature forests with less human interference, trees with differing demands for resources as well as the herb layer of the understorey might "arrange" according to resource availability. Stand transpiration may therefore be more extensively controlled by other stand structural variables; it is not by stand species composition or species diversity in our case. This is in line with conclusions drawn by Roberts (1983), who states that forest transpiration is a rather "conservative 
process" with little variation of transpiration among (differently composed) stands.

In addition, one might also argue that besides a mere tree diversity effect, interactions between tree diversity and certain environmental conditions (e.g. rainfall intensity and duration, evaporative demand, soil water availability, etc.) are crucial. That would explain why relationships between species composition/diversity and throughfall seem to be dependent on prevalent rainfall and weather conditions (Krämer and Hölscher, 2009), and canopy transpiration only differed among diverse and less diverse stands in certain years (Gebauer et al., 2012). This is further supported by the fact that diversity effects on soil water extraction only occurred in certain periods (Krämer and Hölscher, 2010). These findings indicate that it is not only that there is no "magic effect" of biodiversity per se (Hector et al., 2000) (the characteristics of underlying species determine whether tree diversity matters or not), but that it also seems that an ecosystem needs to be subject to specific environmental conditions under which tree diversity can accomplish importance.

Furthermore, more than one characteristic or trait of a species can influence a single ecosystem process (such as water use). These traits may additionally be linked or may counteract each other: the variability of drought sensitivity (high to low: F. sylvatica $>$ A. pseudoplatanus $>$ T. cordata $>$ C. betulus $>F$. excelsior) and water consumption (high to low: F. sylvatica $>$ A. pseudoplatanus $>$ C. betulus $>$ T. cordata $>$ F. excelsior) among tree species in Hainich (Hölscher et al., 2005; Köcher et al., 2009) reveals an almost similar behaviour of species in both parameters. However, it still depends very much on the severity and duration of a given drought event if a certain species uses much water, because it is a big water consumer or because it is very drought-tolerant. In addition, the volume of soil water extraction of a stand is strongly dependent on the percentage mixture of drought-tolerant and high water-using trees, because both act on stand transpiration in differing ways under certain soil water availability. These complex relationships between traits within one species, the combined traits of a mixture as well as between traits and environmental conditions were discussed in a simplified modelling exercise of water use in artificial stands of Fagus, Tilia and Fraxinus (Bittner et al., 2010): Fraxinus was parameterized to have half of the transpiration of Fagus under wet soil conditions (based on findings with uncalibrated sap flux sensors; Gebauer et al., 2012). However, Fraxinus was also set up to maintain high transpiration at much drier soil conditions compared to $\mathrm{Fa}$ gus. It was observed that, at times of high potential transpiration rates accompanied by soil water depletion, modelled Fraxinus monocultures maintained higher water uptake rates compared to times with low evaporative demand and sufficient soil water supply. Modelled Fagus monocultures showed the opposite behaviour: transpiration in wet years was higher compared to dry years, despite the lower evaporative demand during these times, since it was more sensi- tive to declining soil water availability. Thus the differences in soil water uptake between modelled Fagus and Fraxinus monocultures were lower in the dry years than in the wet years. The authors conclude further that, depending on the mixture and the climatic conditions, drought-tolerant species may even exert damage to drought-sensitive species depending on the severity of the drought. We have confidence that no pronounced water stress occurred during the dry spell in 2009 since there was no drop in water uptake during periods of high evaporative demand (Fig. 4), and water uptake from the topsoil layer continued throughout the whole dry spell. Therefore we believe that not "drought tolerance" but "maximum water use rate under wet soil conditions" of the trees was the trait influencing measured soil water uptake by trees here. It remains questionable whether we could have detected an influence of tree diversity on water uptake under more severe drought since Krämer and Hölscher (2010) found that differences in soil water extraction rates of diverse and $F a$ gus-dominated stands in our area disappeared as soil drought advanced.

In summary, we did not find differences in water uptake among single species clusters besides a marginally higher water use of Fraxinus clusters or among tree clusters of differing diversity levels throughout the vegetation period of 2009. We discuss that water use may indeed be a conservative process, that differences in tree-species-specific traits do not necessarily translate into neighbourhood or stand level and that they can be compensated for by one another or by stand parameters such as herb layer and tree spatial arrangement. Furthermore, species identity or diversity effects on stand water use may only arise under certain environmental conditions. Thus, considering effects of tree diversity on stand water use exclusively may not be an appropriate simplification of the complex network of interactions between species traits, stand properties and environmental conditions that have varying influence on stand water use, both in space and time.

Acknowledgements. This study was conducted within the framework of the Research Training Group "Graduiertenkolleg 1086: The role of biodiversity for biogeochemical cycles and biotic interactions in temperate deciduous forests", funded by the DFG (German Research Foundation). We thank Dominik Seidel and Christina Langenbruch for providing data on cluster characteristics and Yann Clough for statistical consultation.

Edited by: J. Stadler

Reviewed by: three anonymous referees 


\section{References}

Bates, D.: lmer, p-values and all that, available at: https://stat. ethz.ch/pipermail/r-help/2006-May/094765.html (last access: 29 April 2013), 2006.

Bittner, S., Talkner, U., Krämer, I., Beese, F., Hölscher, D., and Priesack, E.: Modeling stand water budgets of mixed temperate broad-leaved forest stands by considering variations in species specific drought response, Agr. Forest Meteorol., 150, 13471357, 2010.

Christensen, J. H., Hewitson, B., Busuioc, A., Chen, A., Gao, X., Held, I., Jones, R., Kolli, R. K., Kwon, W.-T., Laprise, R., Magaña Rueda, V., Mearns, L., Menéndez, C. G., Räisänen, J., Rinke, A., Sarr, A., and Whetton, P.: Regional climate projections, Climate Change 2007: the physical science basis, contributions of working group I to the fourth assessment report of the Intergovernmental Panel on Climate Change, edited by: Solomon, S., Cambridge University Press, New York, 2007.

Crockford, R. H. and Richardson, D. P.: Partitioning of rainfall into throughfall, stemflow and interception: effect of forest type, ground cover and climate, Hydrol. Process., 14, 2903-2920 2000.

DWD (Deutscher Wetterdienst, Offenbach), http://www.dwd.de, last access: 20 December 2008.

Gamfeldt, L., Snall, T., Bagchi, R., Jonsson, M., Gustafsson, L., Kjellander, P., Ruiz-Jaen, M. C., Froberg, M., Stendahl, J., Philipson, C. D., Mikusinski, G., Andersson, E., Westerlund, B., Andren, H., Moberg, F., Moen, J., and Bengtsson, J.: Higher levels of multiple ecosystem services are found in forests with more tree species, Nature Communications, 4, 1340, doi:10.1038/ncomms2328, 2013.

Gebauer, T., Horna, V., and Leuschner, C.: Variability in radial sap flux density patterns and sapwood area among seven cooccurring temperate broad-leaved tree species, Tree Physiol., 28, 1821-1830, 2008.

Gebauer, T., Horna, V., and Leuschner, C.: Canopy transpiration of pure and mixed forest stands with variable abundance of European beech, J. Hydrol., 442-443, 2-14, 2012.

Guckland, A., Jacob, M., Flessa, H., Thomas, F. M., and Leuschner, C.: Acidity, nutrient stocks and organic matter content in soils of a temperate deciduous forest with different abundance of European beech (Fagus sylvatica L), J. Plant Nutr. Soil Sc., 172, 500-511, 2009.

Hagger, J. P. and Ewel, J. J.: Primary productivity and resource partitioning in model tropical ecosystems, Ecology, 78, 1211-1221, 1997.

Hector, A., Schmid, B., Beierkuhnlein, C., Caldeira, M. C., Diemer, M., Dimitrakopoulos, P. G., Finn, J. A., Freitas, H., Giller, P. S., Good, J., Harris, R., Hägberg, P., Huss-Danell, K., Joshi, J., Jumpponen, A., Körner, C., Leadley, P. W., Loreau, M., Minns, A., Mulder, C. P. H., O’Donovan, G., Otway, S. J., Pereira, J. S., Prinz, A., Read, D. J., Scherer-Lorenzen, M., Schulze, E.-D., Siamantziouras, A.-S. D., Spehn, E. M., Terry, A. C., Troumbis, A. Y., Woodward, F. I., Yachi, S., and Lawton, J. H.: Plant diversity and productivity experiments in European grasslands, Science, 286, 1123-1127, 1999.

Hector, A., Schmid, A., Beierkuhnlein, C., Caldeira, M. C., Diemer, M., Dimitrakopoulos, P. G., Finn, J. A., Freitas, H., Giller, P. S., Good, J., Harris, R., Högberg, P., Huss-Danell, K., Joshi, J.,
Jumpponen, A., Körner, C., Leadley, P. W., Loreau, M., Minns, A., Mulder, C. P. H., O’Donovan, G., Otway, S. J., Pereira, J. S., Prinz, A., Read, D. J., Scherer-Lorenzen, M., Schulze, E. D., Siamantziouras, A.-S. D., Spehn, E., Terry, A. C., Troumbis, A. Y., Woodward, F. I., Yachi, S., and Lawton, J. H.: Response to Houston et al., Science, 289, p. 1255a, 2000.

Herbst, M., Roberts, J. M., Rosier, P. T. W., Taylor, M. E., and Gowing, D. J.: Edge effects and forest water use: a field study in a mixed deciduous woodland, Forest Ecol. Manage., 250, 176186, 2007.

Hölscher, D., Koch, O., Korn, S., and Leuschner, C.: Sap flux of five co-occurring tree species in a temperate broad-leaved forest during seasonal soil drought, Trees Struct. Funct., 19, 628-637, 2005.

Hooper, D. U., Chapin III, F. S., Ewel, J. J., Hector, A., Inchausti, P., Lavorel, S., Lawton, J. H., Lodge, D. M., Loreau, M., Naeem, S., Schmid, B., Setälä, H., Symstad, A. J., Vandermeer, J., and Wardle, D. A.: Effects of biodiversity on ecosystem functioning: a consensus of current knowledge, Ecol. Monogr., 75, 3-35, 2005.

Jacob, A., Hertel, D., and Leuschner, C.: On the significance of belowground overyielding in temperate mixed forests: separating species identity and species diversity effects, Oikos, 122, 463473, 2013.

Jacob, M., Leuschner, C., and Thomas, F. M.: Productivity of temperate broad-leaved forest stands differing in tree species diversity, Annuals of Forest Science, 67, 503-511, 2010.

Köcher, P., Gebauer, T., Horna, V., and Leuschner, C.: Leaf water status and stem xylem flux in relation to soil drought in five temperate broad-leaved tree species with contrasting water use strategies, Annals of Forest Science, 66, 101-111, 2009.

Krämer, I. and Hölscher, D.: Rainfall partitioning along a tree diversity gradient in a deciduous old-growth forest in Central Germany, Ecohydrology, 2, 102-114, 2009.

Krämer, I. and Hölscher, D.: Soil water dynamics along a tree diversity gradient in a deciduous forest in Central Germany, Ecohydrology, 3, 262-271, 2010.

Kunert, N., Schwendenmann, L., Potvin, C., and Hölscher, D.: Tree diversity enhances tree transpiration in a Panamanian forest plantation, J. Appl. Ecol., 49, 135-144, 2012.

Law, B. E., Falge, E., Gu, L., Baldocchi, D. D., Bakwin, P., Berbigier, P., Davis, K., Dolman, A. J., Falk, M., Fuentes, J. D., Goldstein, A., Granier, A., Grelle, A., Hollinger, D., Janssens, I. A., Jarvis, P., Jensen, N. O., Katul, G., Mahli, Y., Matteucci, G., Meyers, T., Monson, R., Munger, W., Oechel, W., Olson, R., Pilegaard, K., Paw U, K. T., Thorgeirsson, H., Valentini, R., Verma, S., Vesala, T., Wilson, K., and Wofsy, S.: Environmental controls over carbon dioxide and water vapor exchange of terrestrial vegetation, Agr. Forest Meteorol., 113, 97-120, 2002.

LÖWE: 20 Jahre langfristige ökologische Waldentwicklung, LÖWE-Erlass von 2007, Niedersächsischen Landesforsten, 2011.

Meinen, C., Leuschner, C., Ryan, N. T., and Hertel, D.: No evidence of spatial root system segregation and elevated fine root biomass in multi-species temperate broad-leaved forests, Trees, 23, 941950, 2009.

Meinzer, F. C., Bond, B. J., Warren, J. M., and Woodruff, D. R.: Does water transport scale universally with tree size?, Funct. Ecol., 19, 558-565, 2005. 
Meißner, M., Köhler, M., Schwendenmann, L., and Hölscher, D.: Partitioning of soil water among canopy trees during a soil desiccation period in a temperate mixed forest, Biogeosciences, 9, 3465-3474, doi:10.5194/bg-9-3465-2012, 2012.

Mölder, A., Bernhard-Römermann, M., and Schmidt, W.: Forest ecosystem research in Hainich National Park (Thuringia): first results on flora and vegetation in stands with contrasting tree species diversity, Waldökologie online, 3, 83-99, 2006.

Mölder, A., Bernhardt-Römermann, M., and Schmidt, W.: Herblayer diversity in deciduous forests: Raised by tree richness or beaten by beech?, Forest Ecol. Manage., 256, 272-281, 2008.

Mölder, I.: Diversity and tree neighborhood effects on the growth dynamics of European beech and the stand seed bank in temperate broad-leaved forests of variable tree diversity, $\mathrm{Ph} . \mathrm{D}$. thesis, University of Göttingen, 2009.

Morin, X., Fahse, L., Scherer-Lorenzen, M., and Bugmann, H.: Tree species richness promotes productivity in temperate forests through strong complementarity between species, Ecol. Lett., 14, 1211-1219, 2011.

O'Hara, K. L.: The Silviculture of transformation - a commentary, Forest Ecol. Manage., 151, 81-86, 2001.

Paquette, A. and Messier, C.: The effect of biodiversity on tree productivity: from temperate to boreal forests, Glob. Ecol. Biogeogr., 20, 170-180, 2011.

Potvin, C. and Gotelli, N. J.: Biodiversity enhances individual performance but does not affect survivorship in tropical trees, Ecol. Lett., 11, 217-223, 2008.

Pretzsch, H.: Diversity and productivity in forests: evidence from long-term experimental plots, in: Forest diversity and function, Ecological Studies, edited by: Scherer-Lorenzen, M., Körner, Ch., and Schulze, E. D., 176, Springer, Heidelberg, 41-64, 2005.

Pretzsch, H. and Schütze, G.: Transgressive overyielding in mixed compared with pure stands of Norway spruce and European beech in Central Europe: evidence on stand level and explanation on individual tree level, Eur. J. For. Res., 128, 183-204, 2009.

$\mathrm{R}$ Core Team, R: a language and environment for statistical computing, R Foundation for Statistical Computing, Vienna, Austria, http://www.R-project.org/, 2012.

Roberts, J.: Forest transpiration: a conservative hydrological process?, J. Hydrol., 66, 133-141, 1983.

Rowell, D. P. and Jones, R. G.: Causes and uncertainty of future summer drying over Europe, Clim. Dynam., 27, 281-299, 2006.

Schume, H., Jost, G., and Hager, H.: Soil water depletion and recharge patterns in mixed and pure forest stands of European beech and Norway spruce, J. Hydrol., 289, 258-274, 2004.
Seidel, D.: Terrestrial laser scanning - applications in forest ecological research, Dissertation zur Erlangung des Doktorgrades, Georg-August-Universität Göttingen, 9-10, http://hdl. handle.net/11858/00-1735-0000-0006-B3A6-9, 2011.

Seidel, D., Leuschner, C., Scherber, C., Beyer, F., Wommelsdorf, T., Cashman, M. J., and Fehrmann, L.: The relationship between tree diversity, canopy space exploration and productivity in a temperate broad-leafed mixed forest, in review, 2013.

Szwagrzyk, J. and Gazda, A.: Above-ground standing biomass and tree species diversity in natural stands of Central Europe, J. Veg. Sci., 18, 555-562, 2007.

Tilman, D., Lehman, C. L., and Thomson, K. T.: Plant diversity and ecosystem productivity: theoretical considerations, P. Natl. Acad. Sci. USA, 94, 1857-1861, 1997.

Van Peer, L., Nijs, I., Reheul, D., and De Cauwer, B.: Species richness and susceptibility to heat and drought extremes in synthesized grassland ecosystems: compositional vs physiological effects, Funct. Ecol., 18, 769-778, 2004.

Verheyen, K., Bulteel, H., Palmborg, C., Olivié, B., Nijs I., Raes, D., and Muys, B.: Can complementarity in water use help to explain diversity-productivity relationships in experimental grassland plots?, Oecologia, 156, 351-361, 2008.

Vilà, M., Inchausti, P., Vayreda, J., Barrantes, O., Gracia, C., Ibáñez, J. J., and Mata, T.: Confounding factors in the observational productivity-diversity relationship in forests, in: Forest diversity and function, Ecological Studies, edited by: Scherer-Lorenzen, M., Körner, Ch., and Schulze, E. D., 176, Springer, Heidelberg, 65-86, 2005.

Vilà, M., Carrillo-Gavilán, A., Vayreda, J., Bugmann, H., Fridman, J., Grodzki, W., Haase, J., Kunstler, G., Schelhaas, M., and Trasobares, A.: Disentangling biodiversity and climatic determinants of wood production, PLoS ONE, 8, e53530, doi:10.1371/journal.pone.0053530, 2013.

Vockenhuber, E. A., Scherber, C., Langenbruch, C., Meißner, M., Seidel, D., and Tscharntke, T.: Tree diversity and environmental context predict herb species richness and cover in Germany's largest connected deciduous forest, Perspect. Plant Ecol., 13, 111-119, 2011.

Zuur, A. F., Ieno, E. N., Walker, N. J., Saveliev, A. A., and Smith, G. M.: Mixed effects models and extensions in ecology with R, Springer, New York, 2009. 